


\section{REGISTRO Y DIFUSIÓN DEL PERFORMANCE ARTÍSTICO \\ EN LA ERA DIGITAL}

Documentation and dissemination of artistic performance

in the digital age

Santiago Ávila Albuja

\section{Resumen}

El siguiente texto tiene como objetivo indagar en la relación entre performance y nuevas tecnologías, haciendo énfasis en su registro y difusión. Primero se pondrá en contexto el momento en el que surge la era digital y su influencia en las artes visuales y específicamente en el performance. Luego, a partir de la obra de las artistas: Orlan y Amalia Ulman, se evidenciarán distintas metodologías para abordar el registro de performance, dando especial atención a elementos como: el ciberespacio, la simultaneidad de la acción a través de la pantalla y el uso del cuerpo virtual, entre otros. Finalmente se reflexionará acerca de lo que supone para el performance y su registro, enfrentarse a un publico que no puede entender la realidad, sin la mediación de dispositivos tecnológicos.

\section{Abstract}

This text studies the relations between performance and new technologies with emphasis on its recording and diffusion. There is a historical background about the origins and the arrival of digital age, and it's influence in visual arts, and within performance arts. The work of two artists, Orlan and Amalia Ulman, will explain recording performance art's characteristics, taking in account elements such as virtual space, simultaneity of action through the screen and the use of virtual elements. Finally, we will analyze the challenge of recording performance art and it's recording face to an audience unable to understand reality without technological devices.

\section{Key Words:}

Performance, Digital Era, Technology, Recording.

\section{Palabras clave:}

Performance, Era Digital, Tecnología, Registro.

\section{Biografía del Autor:}

Santiago Ávila, 1993 - Quito, Ecuador. Artista Visual graduado por la Pontificia universidad Católica del Ecuador y Máster en Teoría y Crítica de la Cultura por la Universidad Carlos III de Madrid, España. 
Las últimas dos décadas del siglo XX fueron escenario de varias transformaciones en el ámbito de la tecnología y de la comunicación. Una de las más importantes tuvo que ver con la llegada de la era digital, la cual paulatinamente fue reemplazando a distintas herramientas analógicas como: televisión, radio, reproductores de discos de acetato, cámaras fotográficas y de video.

De esta forma se produce una migración hacia nuevos dispositivos con circuitos digitales, que interactúan directamente con computadores y otros medios de almacenamiento que facilitan el intercambio de información, disminuyen el tiempo de registro, edición y producción, al mismo tiempo que permiten mayor eficiencia y accesibilidad al público debido a su bajo coste.

El avance de estas herramientas de comunicación permitió a muchos artistas proponer proyectos que incorporaron el uso de estas nuevas tecnologías digitales. Así surge una nueva corriente que interactuó de forma temprana con la imagen en la red denominada Net Art ${ }^{1}$.

Esto generó gran interés por explorar el espacio virtual, que fue diversificándose y explorando distintos temas como: el uso y creación de bases de datos, la producción de juegos virtuales y la difusión software libre. De esta forma se acuña el término Media art o New media art, que se refiere a las nuevas prácticas artísticas que usan medios tecnológicos digitales. Al respecto el historiador Gunter Berghaus comenta:

El final del siglo XX se convirtió en la era del Media art, de las instalaciones multimedia interactivas que podrían ser exploradas, modificadas y transformadas por el visitante [...] Los medios

1 A mediados de los años noventa, una serie de artistas comienzan a emplear el internet como soporte para obras y proyectos. En esta época de net.art autorreferencial, el núcleo lo forman obras basadas formalmente en códigos de programación web HTML, que experimentan con la nueva posibilidad de colaboración entre artistas o entre artistas y espectadores (Baumgärtel,2009,p.8). electrónicos y digitales inauguran una nueva era de experimentación vanguardista[...] Las Media art del fin-de-milenio se trasladaron a un terreno genuinamente nuevo y reflexionaron sobre los modos alterados de la comunicación, las implicaciones estéticas y sociales, y la forma en que cambiaron radicalmente los modos de interacción de la gente con el mundo que los rodea (Berghaus, 2005, p. 237).

El termino Media art se fundamenta en la interactividad. No se trata simplemente de una exploración superflua en el campo de las nuevas tecnologías, sino que exige a quienes indagan en ellas que el espectador sea parte vital de la experiencia estética y puede interactuar vívidamente con la misma.

Esta búsqueda por la interactividad entre el espectador y la obra de arte se conecta con la corriente del Performance (forma de expresión que utiliza al cuerpo como soporte para la creación de acciones artísticas en vivo). Apareciendo de esta manera el Performance digital, concepto que abarca a todas aquellas prácticas artísticas que tienen una conexión indiscutible con elementos digitales, como define Steve Dixon :

Definimos el término "performance digital" ampliamente para incluir todos los trabajos de actuación donde las tecnologías informáticas juegan un papel clave más que subsidiario en contenido, tecnología, estética o formas de recepción. Esto incluye teatro, danza y arte de performance que incorpora proyecciones que han sido creadas o manipuladas digitalmente; Espectáculos de realidad virtual y robótica; Instalaciones y obras teatrales que utilicen equipos de percepción/activación por ordenador y de técnicas telemáticas; además de obras de net.art (Dixon, 2007, p. 3).

Estos nuevos contenidos que ya se manifestaban desde finales del siglo XX, se expresan en obras de artistas como: Graham Weinbren, Antoni Muntadas, Eija-LiisaAhtila, Kristin Lucas, Jennifer y KevinMcCoy, Paul Sernony y Stelarc ${ }^{2}$. El performance digital se perfila como un nuevo término, cada vez más recurrente en el cual se puede encontrar una hibridación entre cuerpo, arte y tecnología.

Aquí cabe resaltar la figura de la artista francesa Orlan, quien desarrolló su obra a 
partir de la década de 1960, realizando varios performances en relación a la imagen e identidad de la mujer. En 1990 produjo La reencarnación de Santa Orlan, serie en la que se sometió a diversas cirugías plásticas en la que buscaba emular rasgos físicos femeninos característicos ${ }^{3}$ de obras famosas del arte clásico.

Durante su séptima intervención quirúrgica realizada en 1993, en la obra titulada Omnipresence ${ }^{4}$, ella prepara la organización de todo el espacio en el que se realizaría su intervención quirúrgica-artística, escogiendo el vestuario de los doctores, la distribución de los objetos y el color de las paredes, entre otras cosas. La artista decide todos y cada uno de los aspectos formales y conceptuales de la acción a realizar. Sin embargo Orlan agrega un nuevo elemento, que será el que convierta esta per-

\footnotetext{
2 Stelarc es un artista australiano de origen Chipriota, ha simultaneado sus performances corporales, sus suspensio nevents, y sus performances tecnológicas con su tercera mano artificial. El aspecto mas chocante del trabajo de Stelarc vinculado al arte corporal se halla en el hecho de que el artista se suspende en el aire con la ayuda de ganchos clavados a la piel, esto de 1976 a 1989" (Martel, 2004, p. 175).
}

3 Orlan seleccionó la versión de Leonardo de las cejas de la Mona Lisa, la versión de Boticelli de la barbilla de venus, la versión de Gerard de la nariz de Psyché, la versión de Moreau de los labios de Europa, y el ojo de Diana, creado por un Escultor anónimo de la escuela de Fountaineblueau. (Esta selección nos da una lectura extremadamente ingeniosa de la relación de la historia del arte occidental con las mujeres como partes, la broma emerge por la selección de los fragmentos) (Phelan, 2007, p. 73).

\footnotetext{
4 Omniprésence es el nombre de la séptima operación quirúrgica-performance. [...] Por primera vez, la intervención no tiene lugar en Francia, sino en Nueva York, el 21 de noviembre de 1993. Se retransmite en directo a París, a la galería Sandra Gering de New York, al centro Mac Luhan de Toronto y al centro multimedia de Band, también en Canadá. El cuerpo presente en el quirófano en carne y hueso es así simultáneamente visible desde cuatro espacios más y permite a la artista dialogar con los espectadores que asisten a la retransmisión, de ahí el título. (2002, p.106).
}

formance en un referente del cambio de paradigma dentro de la documentación del arte de acción y la relación con las nuevas tecnologías. Durante el transcurso de su operación, decide transmitir en vivo todos estos sucesos a través de una imagen digital en video (enviada vía satélite) que pudo ser observada simultáneamente en tres espacios distintos 5 . Fusionando así la acción corporal, el evento en vivo y el documento difundido simultaneamente.

Esta posibilidad de desmaterializar su cuerpo y transformarlo en información, marcó no sólo su práctica artística, sino también se convirtió en referente para otras obras similares en la venidera época digital. Orlan hizo de esta obra un encuentro con el siguiente milenio, plagado de un sin número de expresiones artísticas que son mediadas por la red digital.

En este obra se produce una mixtura entre el registro digital inmaterial y el objeto que se presenta como material expositivo. Orlan trabaja Omnipresence desde dos líneas. La primera es la producción de varios autorretratos $^{6}$ de su postoperatorio, y la segunda es la grabación que realizó durante la operación, material que convertiría en un video ${ }^{7}$

\footnotetext{
5 La operación marcó una especie de culminación de las exploraciones del arte del performance y de los medios electrónicos que comenzó en los años 1970 y 1980. En "Omnipresence", no había un cuerpo "vivo" mostrándose a la audiencia, fenomenológicamente hablando (estrictamente no había audiencia en el quirófano, a menos que se cuenta Orlan y su equipo médico y de medios). El cuerpo se había saturado digitalmente, exhaustivamente y completamente mediatizado por las imágenes y señales electrónicas que transmitían la cirugía al mundo más allá del quirófano (Ince, 2000, p.104).

6 Además de las fotografías Omniprésence, colgadas en la galería Sandra Gering, Orlan creó toda una serie de retratos, así como una serie de obras de los materiales utilizados en la operación (batas quirúrgicas, gasas y mantas). En las fotografías de retrato tituladas "Este es mi cuerpo, este es mi software"(Blistène, 2004, p.134).
} 
que muestra las acciones sucedidas. Esto le significó agregar elementos y organizar conceptualmente el material a ser presentado. Orlan mezcla lo inmaterial y el uso del documento físico, el cual es procesado para su contacto con el público. Esta necesidad por utilizar el medio tecnológico como parte de su reflexión, hace de su trabajo un referente importante al momento de entender la relación entre nuevos medios y arte contemporáneo.

Con el avance de la interactividad en la red se puede observar que se producen performance que son pensadas en su totalidad para ser difundidas en el ciberespacio, y que no necesariamente requieren de un documento físico que las respalde. Ese es el caso del trabajo de la artista argentina Amalia Ulman, quien ha desarrollado su obra en torno a la construcción de la identidad en tiempos de internet y de dispositivos digitales.

Su trabajo empezó en el año 2012, cuando planteó varios proyectos en los que se interesó por la identidad de la mujer en internet. En 2014 produjo la obra Exellen-

\footnotetext{
7 Esta reflexión acerca del video, tiene que ver con la edición del material, debido a que con las decisiones que se toman en relación al montaje visual y la postproducción, se puede evidenciar como el video es un medio manipulable, que refleja las decisiones conceptuales del artista que interviene sobre él. En el texto Media Performance: along the border (1998) se hace una clara reflexión al respecto.
}

A pesar de las intervenciones tecnológicas que hace posible el sistema de procesamiento electrónico, el video sigue siendo un medio "personal", ya que los efectos de la cámara, grabación y edición están bajo el control total del video productor. El proceso de grabación y edición hace de la creación de vídeo una actividad abstracta y conceptual, y sin embargo aquí llegamos a otra conclusión paradójica, a saber, que la especificidad del video como expresión creativa se contradice por su función como medio de reproducibilidad (Birringer, 1998, p. 146).

Esta simbiosis entre lo reproducible y lo personal es un elemento clave para entender no solo el registro en video de las acciones de performance, sino también de todo tipo de material audiovisual. ces and Perfections, una serie de performances online, registrados en fotografía y video. En esta obra la Amalia Ulman presenta la historia de una mujer que sufre una serie de situaciones personales, que son exhibidas a través de la red social Instagram.

La obra cuestiona distintos parámetros de representación existentes en las redes sociales. Ella trabaja Exellences and Perfections como un engaño, en el que simula la imagen de una mujer cuyo comportamiento refleja ideales inalcanzables del sistema capitalista. Así se somete al escrutinio público de sus seguidores virtuales, quienes a través de las fotografías que la artista publica, comienzan a formar parte de su vida, interactuando ${ }^{8}$ y observando su conducta en la red.

Ulman aparentemente muestra su entorno cotidiano 9 , sin embargo lo que en realidad nos presenta es un guión de acontecimientos irreales. Esta serie de autor representaciones a las cuales se somete, la llevan a asumir com-

\footnotetext{
8 Esta noción de entender al internet como un espacio no solamente de consumo sino también de intercambio y de aportación tiene su origen en el término Web 2.0:
}

La Web 2.0 se centra en las aplicaciones / servicios comunes, como los blogs, el intercambio de vídeo, las redes sociales y el podcasting- una web socialmente más conectada en la que las personas pueden contribuir tanto, como pueden consumir (Anderson, 2007,p. 4).

9 El 19 de abril de 2014, Amalia Ulman subió una imagen a su cuenta Instagram de las palabras "Parte I" en letras negras sobre un fondo blanco. El título leyó, crípticamente, "Exellences y Perfections." Recibió veintiocho likes. Durante los siguientes meses, realizó una presentación en línea con guiones a través de sus perfiles Instagram y Facebook. Como parte de este proyecto, titulado "Exellences y Perfections.", Ulman experimentó una transformación extrema, semi-ficcionada. Ella fingió tener un aumento de pecho, publicando imágenes de sí misma en un vestido de hospital y con un pecho vendado, usando un sujetador acolchado y Photoshop para manipular su imagen (Connor, 2014). 
portamientos y estereotipos que circulan en el ciberespacio ${ }^{10}$, cuestionando a su vez la construcción de un alter ego virtual distinto al que habita el mundo real.

Esta noción de lo auténtico y lo verás en las redes sociales, no solo es reconocido por sus usuarios, también es alentado por sus creadores, quienes buscan cierto grado de autenticidad en sus suscriptores. Creando así una ilusión de identidad e individualidad dentro de los avatares que ocupan este espacio. Como comenta la historiadora del arte.

\section{Cadence Kinsey:}

La autenticidad es una idea central en la cultura de las redes sociales, con frases como 'sé tú mismo' y 'haz lo que amas', frases familiares para la mayoría de los usuarios. Estos ideales son reforzados por la tecnología, ya que las plataformas de medios sociales ahora generalmente requieren - o al menos fomentan - el uso de nombres reales y una sola identidad a través de perfiles (Kinsey, 2016).

De esta manera se entiende la identidad e interrelación humana en dos espacios distintos: uno real y otro virtual. Siendo el segundo el lugar en el que todo es posible y representable.

Ulman a través de sus performances pone en tela de juicio los valores y constructos sociales que están ligados a la identidad y la afectividad. Esta necesidad por recibir constantes estímulos afectivos es, sin duda, un punto interesante en esta reflexión, pues la red se ha convertido en el espacio en el que se reciben afectos y el lugar en donde la economía ha en-

\footnotetext{
10 El espacio cibernético es un espacio simbólico, un reino inmaterial producido electrónicamente que ocupa una posición híbrida entre lo real y lo irreal [...] El ciberespacio no es una alternativa a la esfera cotidiana, sino que está firmemente arraigado en las realidades políticas y económicas que controlan el ciberespacio: las empresas que producen las estaciones de trabajo, los proveedores que dan acceso a la información, las corporaciones globales que transmiten Los códigos binarios, las instituciones que regulan el acceso público, los censores que filtran contenidos indeseables, etc (Berghays, 2015, p. 241).
}

contrado un nicho para depositar su capital, como comenta Juan Martín Prada:

\begin{abstract}
Ahora los productos más exitosos de las nuevas industrias son, sobre todo, las tecnologías de la comunicación, interpersonal, diseñadas específicamente para la explotación del campo de las interacciones sociales y afectivas. De todas las existentes en la segunda década del siglo XXI, las redes sociales en línea lideran la producción de sentimientos relacionados con el bienestar de la compañía y la proximidad, los estados de cercanía y la evidencia continua de afectividad interpersonal ( Prada, 2015, pp. 59-60).
\end{abstract}

Esta hibridación que se da entre afectividad, medios de comunicación e interacción social en la red, es un tópico que acompañará las reflexiones en el nuevo milenio. Con estas intenciones conceptuales Amalia Ulman plantea su proceso de trabajo, inmersa entre las disputas de la representación, la inmaterialidad de la imagen virtual y los límites de la imaginación. La artista argentina nos entrega un relato que estamos dispuestos a creer y que sabemos que puede ser posible. En Exellences and Perfections, extendemos nuestros límites para seguir creyendo en estas representaciones de la mujer, que son irreales y que desde hace décadas ya han sido cuestionadas por un sinúmero de artistas (Cindy Sherman, Barbara Kruger, Nancy Spero, Laurie Anderson, Marina Abramovich, entre otras).

El manejo de las redes sociales ha generado una delgada línea entre las expectativas reales y los discursos construidos por sus usuarios. Estamos inmersos en un contexto en el que una representación de la mujer puede ser entendido como real, así sea cien por ciento fabricado. En este punto volvemos con Juan Martín Prada, quien comenta la obra de Amalia Ulman:

No obstante el elemento de mayor interés de esta performance probablemente radical en su capacidad para operar con las expectativas que es capaz de generar una imagen en las redes sociales y como tendemos a creer $<<$ lo que estamos programados para creer $>$. En efecto, Ulman tematiza nuestra predestinación a generar determinadas conclusiones y narrativas en función de ciertas imágenes y de si estas encajan con nuestro 
<<archivo mental de estereotipos dominantes >>

(Prada, 2015, p. 163).

En este punto retomemos el rol del registro en el performance. Ulman fundamenta su discurso utilizando su cuerpo virtual, artificial y ficticio. Presentándose en las redes a toda hora y en todo momento. Esto supone una desmaterialización del registro físico al mismo tiempo que produce una hibridación entre la acción y su soporte virtual.

No existe imagen original y la obra puede ser copiada o descargada de la web tantas veces como sus usuarios lo deseen. Como comenta Christiane Paul: "La obra de arte en la era de la reproducción digital da por sentado el remezclado y la copia instantáneos, sin degradar la calidad del original a sus múltiplos" (Paul, 2009, p. 134). Esta premisa de reproducción no solo se aplica a la obra de Ulman, sino como comenta Paul a todo tipo de obra que sea trabajada con tecnología digital.

Así podemos divisar que existe un cambio en la recepción de acciones en vivo, pensadas en relación a la interacción virtual. Esto significa un giro dentro del campo del performance, y por ende en la forma en la que se registra. Vale entonces referirnos con mayor detalle a la mirada del público, que ahora más que nunca se enfrenta a una experiencia mediada por pantallas en todo ámbito de su entorno.

En el caso de la performance, y de otros tipos de actuaciones en vivo, se observa que el uso de soportes electrónicos es generalizado. De esta forma nuestra percepción se ha acoplado y acostumbrado a recibir experiencias mixtas que intercalan la imagen real con la virtual. Así lo comenta Philip Auslander:

Mix media performance es la suposición de que la representación en vivo y filmada puede combinarse como lenguajes complementarios e igualmente convincentes, [...] en una producción de medios mixtos que no privilegia ni la teatralidad ni la película (Auslander, 2011, p. 2).

La postura que Auslander propone brinda la posibilidad de intercalar nuestra percepción entre los soportes digitales y la actuación en vivo, cumpliendo cada uno funciones distintas dentro de una performance.

Así las pantallas cumplen la función de un espejo, por medio del cual nos relacionamos con diferentes acciones y cuerpos, los cuales se hibridan a través de las herramientas tecnológicas, para convertirse en dobles virtuales. Estos cuerpos que aparecen en la pantalla de un ordenador o de un móvil se vuelven en cierto modo sus alter egos, en el reflejo de sus cuerpos vivos.

Esto les sucede a Amalia Ulman y Orlan, quienes crean un reflejo virtual en el cual actúan y moldean su identidad, como lo comenta Steve Dixon:

El doble digital puede ser conceptualizado como una forma de reflejo tecnológico del cuerpo vivo, en nuestras categorizaciones estamos definiendo específicamente al doble digital como una imagen que refleja la forma visual idéntica y el movimiento en tiempo real del performer (Dixon, 2007, p. 280).

Esta forma de entender al cuerpo través de la pantalla presenta una entramada relación entre lo real y lo ficticio. Para el performance y su registro esto supone nuevas formas de relación entre el artista y el público, cuestionando el papel y la importancia de la experiencia estética en vivo, y la relación con el registro de acción y sus espacios de difusión. Internet permite generar nuevas dinámicas de interacción entre seres humanos, tecnología e información. La red posee características positivas para el encuentro todo tipo de experiencias artísticas, y a pesar de existir críticas acerca de su construcción y conceptualización, sigue siendo un espacio para democratizar contenidos y recibir experiencias. José Manuel Springer reflexiona:

Las prácticas artísticas críticas como el performance surgieron para dar validez al intercambio directo de contenidos entre el creador y su co-partícipe, el público. Sin embargo, la fragmentación social y la dispersión temporal a la que estamos sujetos en la ciudad, nos impide acceder frecuentemente a esos intercambios específicos 
que propone el performance. La red de internet, que sigue siendo un medio sujeto a fines y usos diversos, propone la desmaterialización de arte, la apertura a nuevas lecturas del cuerpo pero sobretodo propone una democratización, con la cual resulta imposible competir (Springer, 2003).

Las herramientas tecnológicas han trastocado los tiempos y comportamientos en el contexto contemporáneo, haciendo del mundo virtual un espacio vital de interacción. La corriente del arte vivo desde sus inicios a planteado reflexiones críticas hacia la realidad, buscando una interacción directa con el público y siendo un campo político de cuestionamiento a los límites del cuerpo y de la obra de arte.

En un contexto en el que la mirada es mediada por los dispositivos tecnológicos, la búsqueda del performance y de sus registros debe cuestionar la relación entre el sujeto y los estímulos que recibe de la realidad. El campo artístico se ha aproximado a todos estos cuestionamientos de forma profunda (algo lógico) si pensamos que las artes visuales siempre han estado en busca de la innovación y la apropiación de cualquier medio de expresión que puedo plantear reflexiones.

El siglo XXI continúa explorando estas nuevas herramientas digitales, y el arte sigue acompañando y apropiándose de esta evolución tecnológica; siempre con el afán de renovar e intervenir sobre la realidad. Desde la performance, es interesante observar cómo las acciones corporales siguen estando vigentes al momento de cuestionar modelos sociales de comportamiento.

En los casos de Orlan y Amalia Ulman, podemos constatar que, factores como la interactividad, el doble virtual y la simultaneidad de cuerpo dentro de la red, han sido exploraciones posibles gracias al registro de sus acciones y la difusión que los dispositivos digitales les han permitido realizar. Sus obras muestran una relación entre el medio digital y el conceptual. El uso de medios tecnológicos de difusión debe estar acompañado de una metodología que justifique su presencia dentro de la obra.
Confrontar al público a experiencias en las cuales el factor digital es trascendente supone ser conscientes de la relación histórica de la sociedad contemporánea con las imágenes. En especial con dispositivos como: la televisión y el ordenador, medios a través de las cuales se ha construido la realidad de las últimas décadas del siglo XX y principios del siglo XXI.

Tomar conciencia del medio digital implica generar una postura frente a la estructura cultural y social, teniendo claro que la posición del artista es ideológica y conceptual, y por tanto responde a vastas reflexiones que por largo tiempo han criticado el papel de la imagen en la sociedad. Como comenta Jacques Ranciere, la imagen es "un juego complejo de relaciones entre lo visible y lo invisible, lo visible y la palabra, lo dicho y lo no dicho. No es la simple reproducción de lo que ha estado delante del fotógrafo" (Ranciere, 2010, p. 94). Resulta por tanto vital que una propuesta performativa tenga como eje principal el trabajo corporal y la relación reflexiva con el sujeto. De la misma forma, el registro siendo parte indisociable de la acción debe mostrar un contenido crítico, no solo conceptualmente, sino también en relación al medio tecnológico utilizado. Produciendo así obras que sean capaces de detonar nuevas relaciones con el público, quien finalmente da forma a la imagen y la aterriza en la realidad física o virtual.

\section{Bibliografía:}

Auslander, Philip (2011) Liveness: performance in a mediatized Culture. Londres: Routledge.

Berghaus, G. (2005). Avant garde performance: live events and electronic technologies. Hampshire: Palgrave Macmillan.

Blistène, B. (Ed.). (2004). Orlan: carnal art. Paris: Flammarion.

Brea, J (2008) El net art y la cultura que viene. Bogotá: Universidad Nacional de 
Colombia. Facultad de Artes, 2008.

Castillo, J. C. (2004). Arte en la red. Madrid: Cátedra.

Del Val, J. (2011). METAHUMANO / METAPERFORMANCE /METASEXO. En Universos y metaversos: aplicaciones artísticas de los nuevos medios (pp. 61-74). Barcelona: Grupo de Investigación Arte, Arquitectura y Sociedad Digital.

Dixon, S. (2007) Digital Performance. Cambridge, MA: The MIT Press

Ince, K. (2000). Orlan: millennial female. Oxford: Berg.

Lovejoy, M. (2004). Digital currents: art in the electronic age. New York, NY:

Routledge.

Malloy, J. (2003). Women, art, and technology. Cambridge, MA: The MIT Press.

Paul, C. (2008). Digital art. Londres: Thames \& Hudson.

Prada, J. M. (2015). Prácticas artísticas e internet en la época de las redes sociales. Tres Cantos, Madrid: Akal.

Ranciere, J. (2010). El espectador emancipado. Buenos Aires: Manantial.

Romano, G. (2009). Net art 0.1 - Desmontajes: Badajoz: MEIAC.

Rush, M. (2002). Nuevas expresiones artísticas a finales del siglo XX. Barcelona: Destino Ediciones.

\section{Bibliografía en la web:}

Jobey, L. (2016). Hold Still: Performing for the Camera at the Tate Modern. Tate Etc.,(36), spring 2016. Retrieved August 10, 2017, from:

http://www.tate.org.uk/context-comment/ articles/hold-still

Kinsey, C. (2016, March 7). The Instagram artist who fooled thousands. BBC - Culture.

Retrieved August 15, 2017, from:

http://www.bbc.com/culture/ story/20160307-the-instagram-artist-whofooled-thousands

Springer, J. M. (2003, June 1). Performance e Internet. Retrieved August 12, 2017, from: http://www.replica21.com/archivo/ articulos/s t/165 springer internet.html 